\title{
Rancang Bangun Sistem Pengendalian Pintu Garasi Otomatis Dengan Indikator RFID Dan Alarm Berbasis Mikrokontroler
}

\author{
Efrizon $^{1}$, Herizon $^{2}$, Widya Rahayu Dinata ${ }^{3}$ \\ ${ }^{123}$ Jurusan Teknik Elektro Politeknik Negeri Padang \\ Efrizon_s@yahoo.co.id \\ Kampus Politeknik Negeri Padang, Limau Manis Padang
}

\begin{abstract}
High crime along with the development of technology and today causes security systems to be an absolute necessity to be applied, in order to protect assets and the privacy they have. It is expected that by implementing the security system, it can provide a sense of security and comfort, as well as reduce the crime rate that occurs in the community, especially the crime of theft. Crime theft often occurs around the house, such as theft in the garage by breaking into the garage door. Besides human security, it also wants a system that is more practical and easy to use garage doors. Because some people are lazy to open and close the garage door especially if it is raining. The operation of this tool can be started by detecting RFID tags into the RFID reader as input, so that later it will activate a servo motor. Sensor Ping serves to detect the distance of the car to open and close the garage door automatically. The distance on the ping sensor can be adjusted as needed. After testing RFID tags can only be read by RFID readers from a distance of $1 \mathrm{~cm}-3 \mathrm{~cm}$. In this tool use the buzzer as an alarm if the RFID card is wrong and the garage door is vibrated.
\end{abstract}

Keywords: Arduino UNO, RFID Tag, RFID Reader, Ping Sensor, Buzzer, Servo Motor.

Abstrak - Kriminalitas yang tinggi seiring perkembangan teknologi dan zaman sekarang ini menyebabkan sistem keamanan menjadi kebutuhan mutlak untuk diterapkan, guna melindungi aset dan privasi yang dimiliki. Diharapkan dengan penerapan sistem keamanan tersebut, dapat memberi rasa aman dan nyaman, serta menekan angka kriminalitas yang terjadi di masyarakat khususnya tindak kejahatan pencurian. Tindak kejahatan pencurian banyak terjadi di sekitar rumah, seperti pencurian di dalam garasi dengan cara membobol pintu garasi. Disamping keamanan manusia juga menginginkan sistem yang lebih praktis dan mudah dalam penggunaan pintu garasi. Karena sebagian orang malas untuk membuka dan menutup pintu garasi apalagi jika keadaan hujan. Pengoperasian alat ini dapat dimulai dengan pendeteksian tag RFID ke reader RFID sebagai input, sehingga nantinya akan mengaktifkan sebuah motor servo. Sensor Ping berfungsi sebagai pendeteksi jarak mobil untuk membuka dan menutup pintu garasi secara otomatis. Jarak pada sensor ping dapat diatur sesuai dengan kebutuhan. Setelah dilakukannya pengujian tag RFID hanya dapat dibaca oleh reader RFID dari jarak $1 \mathrm{~cm}-3 \mathrm{~cm}$. Pada alat ini menggunakan buzzer sebagai alarm jika kartu RFID salah dan pintu garasi digetarkan.

Kata kunci: Arduino UNO, Tag RFID, Reader RFID, Sensor Ping, Buzzer, Motor Servo.

(C) 2017 Elektron Jurnal Ilmiah

\section{PENDAHULUAN}

Kriminalitas yang tinggi seiring perkembangan teknologi dan zaman sekarang ini menyebabkan sistem keamanan menjadi kebutuhan mutlak untuk diterapkan, guna melindungi aset dan privasi yang dimiliki. Diharapkan dengan penerapan sistem keamanan tersebut, dapat memberi rasa aman dan nyaman, serta menekan angka kriminalitas yang terjadi di masyarakat khususnya tindak kejahatan pencurian.

Tindak kejahatan pencurian banyak terjadi di sekitar rumah, seperti pencurian di dalam garasi dengan cara membobol pintu garasi. Pintu garasi adalah pintu yang biasanya digunakan untuk jalan keluar masuk kendaraan. Karena keamanan yang dijadikan sebagai prioritas utama, biasanya seseorang akan memberikan kunci pada pintu garasi, namun terkadang kunci itu bisa hilang atau diduplikat oleh pihak yang tidak bertanggung jawab dan mudahnya pembobolan dilakukan pada kunci pintu garasi.

Disamping keamanan manusia juga menginginkan sistem yang lebih praktis dan mudah dalam penggunaan pintu garasi. Karena sebagian orang malas untuk membuka dan menutup pintu garasi apalagi jika keadaan hujan.

Banyak ragam alat yang menerapkan teknologi RFID yang telah dibuat. Salah satunya adalah Rio Agusta Wardana[1] dengan judul, dimana pada penelitiannya menggunakan Id Card RFID sebagai input untuk membuka pintu garasi dari luar dan sensor PING sebagai input untuk menutup dan membuka dari dalam secara otomatis. Pada alat ini hanya sistem pengendalian pintu garasi yang diperhatikan, sedangkan sistem keamanan pintu garasi belum diperhatikan. Tujuan dari penelitian ini adalah merancang dan membuat alat pengendali pintu garasi 
secara ototmatis dan praktis menggunakan RFID dengan sistem keamanan yang berbasis mikrokontroller.

\section{METODE PENELITIAN}

Perancangan alat dibuat untuk membantu dan mempermudah dalam mengerjakan alat yang akan dibuat. Perancangan alat dimulai dari pembuatan blok diagram dimana setiap blok tersebut mempunyai fungsi tersendiri yang saling terkait sehingga membentuk sistem dari alat yang akan dibuat. Adapun blok diagram sistemnya dapat dilihat pada gambar 1 dibawah ini.

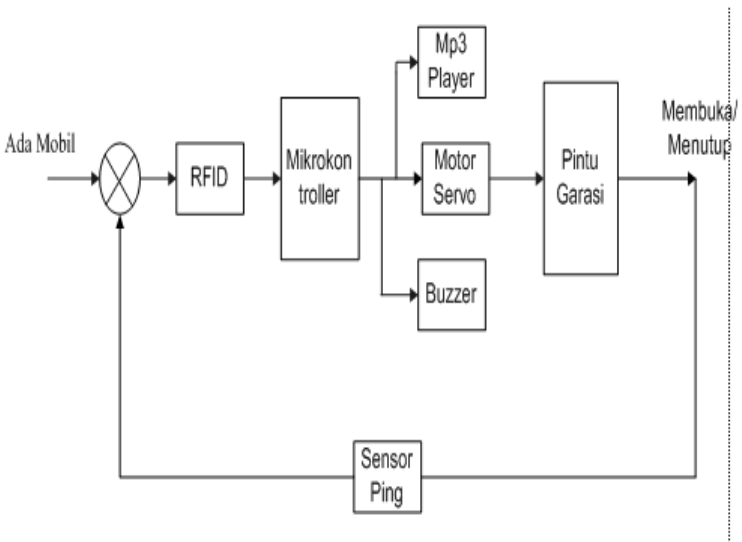

Gambar 1. Blok diagram Sistem

Berdasarkan blok diagram di atas dapat dideskripsikan bahwa prinsip kerja dari Sistem Pengendalian Pintu Garasi Otomatis Dengan Indikator Rfid Dan Alarm Berbasis Mikrokontroller adalah semua intruksi untuk menjalankan alat ini terdapat pada mikrokontroller Arduino uno dengan Atmega328 sebagai pengendali sistem secara keseluruhan. Alat ini menggunakan modul RFID yang berfungsi sebagai komunikasi data yang nantinya digunakan untuk mengirim data ke arduino. Ketika RFID card yang digesek ke modul RFID benar maka mikrokontroller akan mengolah data tersebut sehingga motor servo berputar 90 derajat menyebabkan pintu garasi terbuka dan akan muncul audio "Akses diterima, Silahkan Masuk" dari speaker. Ketika mobil berada $<=4 \mathrm{~cm}$ dari dinding belakang yang dibaca oleh sensor Ping maka akan dikirimkan data ke mikrokontroller agar motor servo berputar sampai 0 derajat dan dapat menutup pintu garasi secara otomatis. Dan pintu garasi akan otomatis terbuka dari dalam ketika mobil berada pada jarak $>6 \mathrm{~cm} \& \&<30 \mathrm{~cm}$ yang akan dibaca oleh sensor Ping serta akan menutup secara otomatis jika mobil berada $>30 \mathrm{~cm}$ dari sensor Ping dan akan ada audio "Selamat Jalan" dari Speaker . Buzzer akan berbunyi ketika RFID card yang digesek ke modul RFID salah dan sensor Vibrasi mendeteksi adanya getaran. Untuk menghentikan bunyi buzzer gesekan kartu RFID pada modul RFID.

\section{A. Perancangan Hardware}

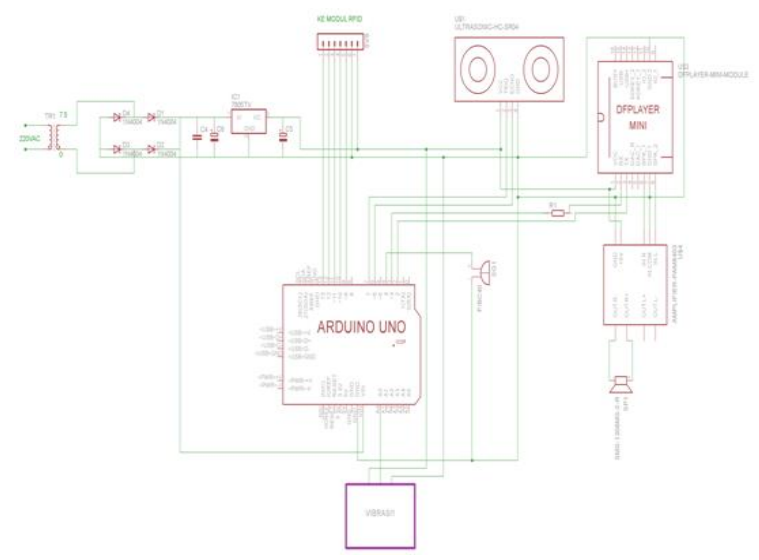

Gambar 2. Skematik Rangkaian Keseluruhan

Rangkaian power supply berfungsi sebagai sumber tegangan utama dari alat yang akan dibuat. Rangkaian power supply memanfaatkan tegangan dari PLN sebesar 220 V_AC. Dengan keluaran tegangan pada sistem dibuat $9 \mathrm{~V}$ _AC menggunakan trafo step down 1 ampere. Output ini telah sesuai dengan menggunakan IC 7805. Rangkaian modul RFID bertujuan menentukan hubungan pin-pin modul RFID ke mikrokontroller yang terhubung pada pin $9-13$. Rangkaian modul Ultrasonic bertujuan menentukan jarak mobil untuk dilakukan proses membuka dan menutup pintu garasi secara otomatis yang terhubung pada pin 6-7 pada mikrokontroler. Rangkaian modul Vibrasi bertujuan untuk mengetahui adanya kegiatan pembobolan pada pintu garasi. Jika modul vibrasi aktif maka akan diproses oleh mikrokontroller dan output akan ditampilkan oleh buzzer berupa alarm, modul ini terhubung pada pin 2. Rangkaian modul Mp3 Player terhubung pada pin 3, sedangkan buzzer yang berfungsi sebagai keamanan untuk pintu garasi terhubung pada pin 4.

\section{B. Perancangan Software}

Perancangan software dimulai setelah perancangan hardware dilakukan. Hal ini dilakukan karena software yang berfungsi untuk mengendalikan peralatan tersebut. Untuk mempermudah perancangan software maka terlebih dahulu dibuat sebuah flow chart untuk menggambarkan jalannya program secara keseluruhan terhadap sistem. Flowchart ini dirancang untuk sistem pintu garasi secara otomatis dengan indikator RFID dan alarm, seperti yang terlihat pada gambar 3 . 


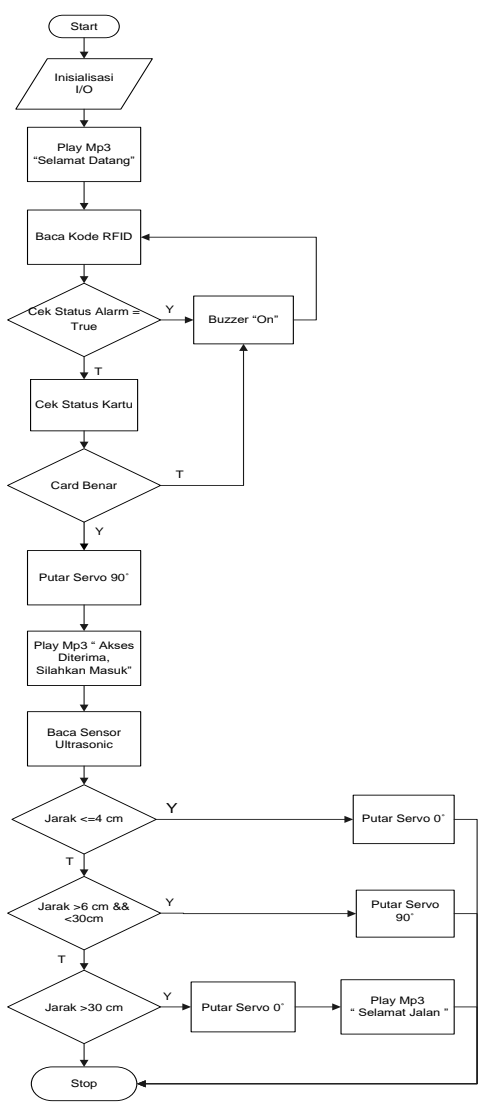

Gambar 3. Flowchart Sistem Pengendalian Pintu Garasi Otomatis

Algoritma sistem kerja alat diatas dapat diuraikan sebagai berikut :

1. Input alat tersebut adalah Kartu RFID, Sensor Ping, dan Sensor Vibrasi. Sedangkan output adalah Motor Servo untuk membuka/ menutup pintu garasi, MP3 player untuk output suara, dan buzzer sebagai bunyi untuk peringatan adanya maling serta kartu yang digesekkan salah.

2. Modul RFID membaca status kartu yang digesekkan.

3. Sensor Vibrasi untuk membaca adanya getaran pada pintu garasi serta membaca status kartu RFID yang salah.

4. Jika kartu yang dimasukkan salah dan pintu garasi bergetar maka Buzzer akan berbunyi.

5. Sensor Ping membaca jarak mobil.

6. Kemudian data yang di peroleh akan di proses oleh mikrokontroler dan dilanjutkan sebagai proses membuka dan menutup pintu garasi oleh motor servo.

\section{HASIL DAN PEMBAHASAN}

Pengujian merupakan salah satu langkah penting yang harus dilakukan untuk mengetahui apakah sistem yang dibuat telah sesuai dengan yang direncanakan, hal itu dapat dilihat dari hasil - hasil yang diperoleh dalam pengujian sistem. Gambar 4 merupakan garasi mobil yang telah dibuat.

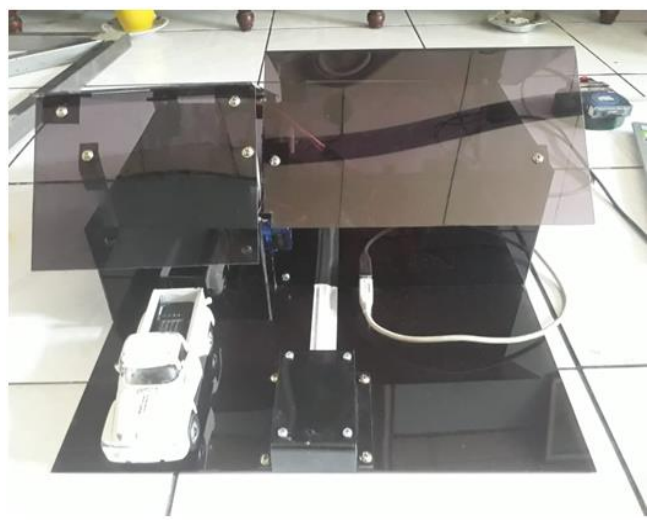

Gambar 4. Pengendalian Pintu Garasi Otomatis

Pengujian dan analisa alat pengendalian pintu garasi otomatis dengan indikator RFID dan alarm yakni:

1. Sensor Ping

2. RFID

3. Motor Servo

\section{A. Pengujian dan analisa Sensor Ping}

Pengujian pada sensor Ping berfungsi untuk mengetahui tegangan pada pin echo dan triger pada jarak sensor ping dengan mobil. Titik pengukuran sensor ping dapat dilihat pada gambar 5 dibawah ini. Hasil pengukuran dapat dilihat pada tabel 1 .

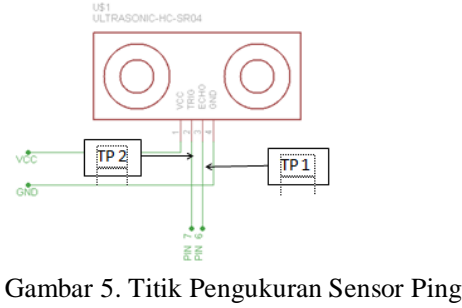

Tabel 1. Pengukuran Tegangan Echo dan Tegangan Triger Pada Sensor Ping

$\begin{array}{ccc}\text { Jarak Mobil dengan } & \text { Tegangan Echo } & \text { Tegangan Triger } \\ \text { Sensor Ping }(\mathrm{cm}) & (\mathrm{mV}) & (\mathrm{mV})\end{array}$

\begin{tabular}{lll}
\hline 2 & 4 & 1 \\
\hline 4 & 2 & 1 \\
\hline 6 & 3 & 1 \\
\hline 8 & 4 & 1 \\
\hline 10 & 5 & 1 \\
\hline 15 & 7 & 1 \\
\hline 20 & 9 & 1
\end{tabular}




\begin{tabular}{ccc}
\hline 25 & 12 & 1 \\
\hline 30 & 15 & 1 \\
\hline
\end{tabular}

Dari tabel 1 diatas didapat analisa bahwa pada tegangan echo, semakin besar jarak pengukuran maka nilai nya akan semakin tinggi. Untuk jarak yang digunakan pada sistem alat ini adalah $4 \mathrm{~cm}, 6 \mathrm{~cm}$ dan $30 \mathrm{~cm}$. Tegangan triger pada sensor ping adalah sama 1 $\mathrm{cm}$. Nilai tegangan triger berfungsi sebagai pemicu sensor ping dalam memantulkan jarak pada tegangan echo, sehingga nilai tegangan triger selalu konstan.

\section{B. Pengujian dan analisa RFID}

Tipe RFID yang digunakan pada alat ini adalah MFRC 522. Langkah Pengujian Jarak Pembacaan RFID adalah Menempelkan kartu RFID pada tag RFID, dan mengukur jarak pembacaan RFID dengan menggunakan mistar. Hasil Pengujian Jarak Pembacaan RFID dapat lihat pada tabel 2.

Tabel 2. Hasil Pengujian Jarak Pembacaan RFID

\begin{tabular}{ccc}
\hline $\begin{array}{c}\text { Jarak Pembacaan } \\
\text { antara reader dan } \\
\text { tag RFID }(\mathrm{cm})\end{array}$ & $\begin{array}{c}\text { Tegangan Input } \\
\text { RFID } \\
(\text { Volt })\end{array}$ & Keterangan \\
\hline 1 & 3,34 & Terdeteksi \\
\hline 2 & 3,34 & Terdeteksi \\
\hline 3 & 3,34 & Terdeteksi \\
\hline 4 & 0 & Tidak Terdeteksi \\
\hline 5 & 0 & Tidak Terdeteksi \\
\hline 7 & 0 & Tidak Terdeteksi \\
\hline
\end{tabular}

Dari tabel 2 diatas didapat lah analisa bahwa tag RFID dapat membaca kartu RFID sampai jarak terjauh sebesar $3 \mathrm{~cm}$. Kondisi pembacaan kartu pada tag RFID ini dapat dilakukan dengan cara menempelkan kartu RFID dalam kondisi setengah fisik kartu maupun sepenuh fisik kartu. Ini dapat terjadi karena pada kartu RFID terdapat garis yang melingkari kartu RFID membentuk persegi panjang dengan microchip ditengah nya. Semua garis tersebut terhubung yang mengakibatkan tag RFID dapat membaca kartu jika garis tersebut terdeteksi meskipun hanya dalam keadaan stengah fisik kartu. Tag RFID dapat membaca kartu RFID dikarenakan data yang terbaca pada tag RFID sama dengan data yang tersimpan di mikrokontroller, karena tag RFID bersifat sebagai komparator. Dalam pengujian ini juga didapatkan bahwa RFID akan dapat membaca kartu ketika tegangan keluaran nya mencapai 3,34 V. Ketika tegangan RFID $0 \mathrm{~V}$ maka tag RFID tidak dapat membaca kartu.

Selanjutnya dilakukan pengujian menempelkan kartu RFID pada tag RFID dengan cara memberi penghalang, yakni plastik kaca, kain tipis, kertas, akrilik, kaca transparan, kayu dan besi. Hasil Pengujian RFID Jika diberi Penghalang dapatdilihat pada tabel 3.

Tabel 3. Hasil Pengujian Jarak Pembacaan RFID diberi penghalang

\begin{tabular}{ccc}
\hline $\begin{array}{c}\text { Tipe Material } \\
\text { Penghalang Kartu } \\
\text { RFID }\end{array}$ & $\begin{array}{c}\text { Tegangan Input } \\
\text { RFID } \\
\text { (Volt) }\end{array}$ & Keterangan \\
\hline Plastik Kaca & 3,34 & Terdeteksi \\
\hline Kain Tipis & 3,34 & Terdeteksi \\
\hline Kertas & 3,34 & Terdeteksi \\
\hline Akrilik & 3,34 & Terdeteksi \\
\hline Kaca Transparan & 3,34 & Terdeteksi \\
\hline Kayu & 0 & Tidak Terdeteksi \\
\hline Besi & 0 & Tidak Terdeteksi \\
\hline
\end{tabular}

Berdasarkan tabel 3 di atas dapat dianalisa bahwa setelah dilakukan pengujian kemampuan RFID untuk membaca status kartu jika diberi material penghalang, RFID tidak dapat membaca status kartu ketika dihalangi oleh kayu dan besi. Namun RFID dapat membaca status kartu jika di halangi oleh plastik kaca, kain tipis, kertas, akrilik dan kaca transparan. Tag RFID dapat membaca kartu meskipun dihalangi oleh plastik kaca, kain tipis, kertas, akrilik dan kaca transparan dikarenakan kondisi material fisik material penghalang yang dapat melewatkan cahaya, sehingga tag RFID tetap dapat membaca coil yang ada pada kartu RFID. Ketebalan material penghalang yang tipis pun menjadi faktor pendukung lainnya untuk tag RFID dapat membaca coil kartu. Sedangkan pada kayu dan besi yang bersifat tidak dapat melewatkan cahaya maka tag RFID tidak bisa membaca kartu RFID. Kondisi fisik materia kayu dan besi yang memiliki ketebalan besar pun menjadi faktor kenapa cahaya tidak dapat dilewatkan. Dari tabel diatas juga didapatkan bahwa meskipun diberi penghalang, tegangan RFID tetap sama yanki 3,34 V ini dikarenakan RFID hanya dapat bekerja mengaktifkan tag RFID pada tegangan keluaran 3,34 V. Pada pengujian ini didapatkan bahwa tag RFID dapat membaca kartu RFID meskipun dihalangi oleh material yang bergantung pada bahan pembuatannya. 
Apabila material penghalang dapat melewatkan cahaya maka tag RFID tetap membaca kartu.

\section{Pengujian dan analisa Motor Servo}

Pengujian pada motor servo dilakukan untuk melihat apakah motor dapat bekerja dengan baik. Pengujian dilakukan dengan cara melihat perputaran motor servo ketika sistem dijalankan. Selanjutnya adalah pengujian motor servo dengan menggunakan osciloscope untuk melihat lebar pulsa yang diberikan sebagai penentu posisi sudut putaran dari motor servo. Pengujian dilakukan terhadap 2 sudut putaran, yaitu $0^{\circ}$ dan $90^{\circ}$. Gambar 6 adalah rangkaian pengujian dan hasil pengujian dari respon servo. Hasil pengujian pada motor servo dapat dilihat pada tabel 4 dan tabel 5 .

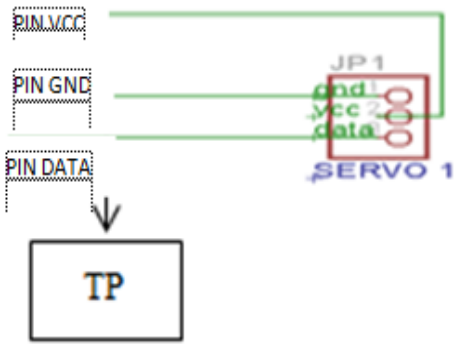

Gambar 6. Titik pengukuran motor servo

Tabel 4. Kondisi Pengontrolan Motor Servo

\begin{tabular}{|c|c|c|}
\hline $\begin{array}{l}\text { Status Pembacaan } \\
\text { Kartu RFID }\end{array}$ & $\begin{array}{c}\text { Putaran } \\
\text { Motor Servo }\end{array}$ & $\begin{array}{l}\text { Keadaan Pintu } \\
\text { Garasi }\end{array}$ \\
\hline Kartu RFID benar & $90^{\circ} \mathrm{CW}$ & Terbuka dari luar \\
\hline $\begin{array}{c}\text { Mobil maju, Sensor } \\
\text { Ping terdeteksi } \\
<=4 \mathrm{~cm}\end{array}$ & $90^{\circ} \mathrm{CCW}$ & $\begin{array}{l}\text { Tertutup dari } \\
\text { dalam }\end{array}$ \\
\hline $\begin{array}{l}\text { Mobil mundur, } \\
\text { Sensor Ping } \\
\text { terdeteksi }<=6 \mathrm{~cm}\end{array}$ & $90^{\circ} \mathrm{CW}$ & $\begin{array}{l}\text { Pintu Terbuka } \\
\text { Otomatis }\end{array}$ \\
\hline $\begin{array}{c}\text { Mobil mundur, } \\
\text { Sensor Ping } \\
\text { terdeteksi }<=30 \mathrm{~cm}\end{array}$ & $90^{\circ} \mathrm{CCW}$ & $\begin{array}{l}\text { Pintu Tertutup } \\
\text { Otomatis }\end{array}$ \\
\hline
\end{tabular}

Tabel 5. Hasil pengujian respon motor servo

\begin{tabular}{|c|c|c|c|}
\hline \multirow{2}{*}{ No } & \multirow{2}{*}{$\begin{array}{l}\text { Sudut putaran } \\
\text { Motor Servo }\end{array}$} & \multicolumn{2}{|c|}{ Lebar pulsa } \\
\hline & & T ON (ms) & $\mathrm{T}$ OFF $(\mathrm{ms})$ \\
\hline 1 & $0^{\circ}$ & 0.55 & 9.45 \\
\hline 2 & $90^{\circ} \mathrm{CW}$ & 1.50 & 8.50 \\
\hline
\end{tabular}

Pada pengujian motor servo diatas dapat di analisa bahwa motor servo dapat berputar untuk membuka dan menutup pintu garasi dikarenakan meliki driver yang menjadi otak pengendali motor servo yang terhubung pada mikrokontroller. Perputaran motor servo dibagi dua yaitu $\mathrm{CW}$ (Counter Wise) dimana perputaran motor servo searah jarum jam yang menyebabkan pintu garasi membuka. Keadaan CW menghasilkan lebar pulsa sebesar $\mathrm{T} \mathrm{ON}=0,55 \mathrm{~ms}, \mathrm{~T}$ $\mathrm{OFF}=9,45 \mathrm{~ms}$, sehingga menghasilkan duty cycle sebesar $5,5 \%$. Perputaran motor servo yang lainnya adalah CCW (Counter Clock Wise) yakni perputaran berlawanan arah jarum jam yang menyebabkan pintu garasi menutup. Keadaan $\mathrm{CCW}$ menghasilkan $\mathrm{T} \mathrm{ON}=$ 1,50 $\mathrm{ms}$, T OFF $=8,50 \mathrm{~ms}$, sehingga menghasilkan duty cycle sebesar $15 \%$.

\section{IV.KESIMPULAN}

1. Tag RFID dapat membaca kartu pada jarak maksimum $3 \mathrm{~cm}$ untuk dapat membuka pintu garasi dan mematikan alarm apabila berbunyi.

2. Jarak pada sensor Ping dapat diatur sesuai keinginan dengan menggunakan mikrokontroller, dimana jarak mobil yang digunakan untuk membuka pintu garasi dari dalam $\geq 6 \mathrm{~cm}$, sedangkan jarak mobil untuk menutup pintu garasi dari dalam $\leq 4 \mathrm{~cm}$.

3. Perputaran motor servo yang digunakan pada Tugas Akhir ini adalah $90^{\circ}$ dan $0^{\circ}$ dengan duty cycle pada sudut $90^{\circ}$ sebesar $15 \%$ dan duty cycle pada sudut $0^{\circ}$ sebesar $5,5 \%$.

4. Ketika kartu RFID yang dimasukkan benar, maka pintu garasi akan secara otomatis membuka dengan menggerakan motor servo $90^{\circ}$. Saat mobil berjarak $4 \mathrm{~cm}$ dari sensor ping, pintu garasi akan secara otomatis menutup dari dalam dengan menggerakkan motor servo $0^{\circ}$. Dan ketika jarak mobil $6 \mathrm{~cm}$ dari sensor ping, maka pintu garasi akan secara otomatis membuka dari dalam. Setelah jarak mobil $30 \mathrm{~cm}$ dari mobil, pintu garasi akan secara otomatis menutup.

\section{REFERENSI}

[1] Marliana Sari. Protype Pengamanan Pintu Dengan Menggunakan Android Dan Embedded Sistem Nirkabel. Jurnal Ilmiah Info Volume VII/No. 1/Mei/2015 . hal 61-74

[2] Ai Fitri Silvia, Erik Haritman, Yuda Muladi. Rancang Bangun Akses Kontrol Pintu Gerbang Berbasis Arduino Dan Android. ELECTRANS, VOL.13, NO.1, MARET 2014, 1-10

[3] Yogie El Anwar, NoerSoedjarwanto,,Ageng Sadnowo Repelianto. Prototype Penggerak Pintu Pagar Otomatis Berbasis Arduino Uno ATMEGA 328P dengan Sensor Sidik Jari. ELECTRICIAN - Jurnal Rekayasa dan Teknologi Elektro Volume 9, No. 1, Januari 2015. Hal 30-41

[4] Hemant Chaudhary ; Prateek Bansal ; B. Valarmathi. Advanced CAR parking system using Arduino. 2017 4th International Conference on Advanced Computing and Communication Systems (ICACCS). India

[5] Dharmini Kanteti ; D V S Srikar ; T K Ramesh. Intelligent smart parking algorithm. 2017 International Conference On Smart Technologies For Smart Nation (SmartTechCon). India 
[6] Qian Zhou ; Fan Ye ; Xiaoge Wang ; Yuanyuan Yang. Automatic construction of garage maps for future vehicle navigation service. 2016 IEEE International Conference on Communications (ICC). Malaysia

[7] Erdal Irmak, Ersan Kabalci, Ali Köse. Design and implementation of a computer interacted smart home system based on PLC. 2010 4th International Conference on Application of Information and Communication Technologies. Uzbekistan

[8] R.Kannadasan, A.Krishnamoorthy, N.Prabakaran N.Prabakaran, K.Naresh, V.Vijayarajan, G.Sivashanmugam. RFID Based Automatic Parking System. Australian Journal of Basic and Applied Sciences 10(2):186-191
[9] Oktavianus, Rendy dkk. "Rancang Bangun Gerbang Keamanan Berbasis RFID ID-12 Pada Perpustakaan”. Bandar Lampung: Universitas Lampung.

[10] Wardana, Rio Agusta. 2014. "Perancangan Pengendalian Pintu Garasi Secara Otomatis Dengan Id Card Berbasis Mikrokontroller". Tugas Akhir. Padang: Politeknik Negeri Padang.

[11] Wibowo, Sunu Hasta. 2014. "Simulasi Pengontrolan Pintu Garasi Otomatis”. Banjarmasin: Politeknik Negeri Banjarmasin. 